\title{
'TE GEVAARLIJK VOOR HET HUISALTAAR': DE ZUID-INDIASE GOD KARUPPANNASAMY
}

\begin{abstract}
Naast pan-Indiase goden zoals Shiva en Vishnu kent India nog een hele reeks lokale godheden en vergoddelijkte helden die verbonden zijn met een streek of clan. Hun beelden zijn zelden aanwezig in kunstmusea, ${ }^{2}$ zowel in India als daarbuiten. Maar vorig jaar werd de collectie van de Vereniging van Vrienden der Aziatische Kunst (VVAK) verrijkt met een beeld van een dergelijke lokale god (afb. 1), dat nu tussen andere objecten uit India staat op de bovenverdieping van het Aziatisch Paviljoen.
\end{abstract}

\section{Iconografie en de naam}

Het beeld is een geschenk van de heer Jaap Polak ter gelegenheid van het 90-jarig jubileum van de VVAK. Het is gemaakt van een koperlegering en stelt een zelfverzekerde jonge man voor. De man staat rechtop, zijn rechterbeen lichtjes gebogen. In zijn rechterhand houdt hij een grote sikkel vast (Tamil: arival/aruval), terwijl zijn linkerhand steunt op een knots. Aan zijn riem hangt een bijzonder mes waarvan het handvat de vorm heeft van een parkiet. De man draagt een korte broek met daarop een brede riem of een sjerp met een complex dessin. Zijn haar is aan de zijkant samengebonden in een chignon. Hij is getooid met sieraden: een diadeem, oorbellen, een brede ketting, een lange ketting met een medaillon, armbanden en enkelbanden, en, zoals het een jongeman betaamt draagt hij een snor. Op zijn voorhoofd is het 'Vaishnava-naman', het teken van Vishnu, weergegeven als een kleine verticale streep. ${ }^{3}$ Dankzij dit voorhoofdteken, de attributen en de haardracht is hij vrijwel zeker te identificeren als Karuppannasamy, 'de zwarte god' (Tamil: karuppu $=$ zwart), een lokale god uit Tamil Nadu. ${ }^{4}$

Er zijn verschillende vormen van Karuppannasamy: Periya en Cinna Karuppu ('grote' en 'kleine' Karuppu), Muttukkaruppu ('parel-Karuppu'), Sangili Karuppu ('Karuppu met een ketting'), Nonti Karuppu ('manke Karuppu'), enzovoorts. Net als bij Shiva of Vishnu kunnen de vormen van Karuppannasamy nogal verschillen van de 'basisvorm' (Nonti Karuppu bijvoorbeeld steunt op een knie), maar over het algemeen is de iconografie van Karuppannasamy niet gestandaardiseerd en zijn sommige vormen vrijwel identiek. Daarom is voor een juiste identificatie de context uiterst belangrijk: waar komt het beeld vandaan en met welke naam is het bekend onder de lokale bevolking? Helaas ontbreekt deze informatie in geval van 'ons' beeld. Wel bekend is dat het beeld al in 1954 in Nederland was, want het is gepubliceerd in de catalogus die werd uitgebracht ter gelegenheid van het 25 -jarig bestaan van de Amsterdamse kunsthandel Aalderink. In die catalogus wordt vermeld dat het beeld deel zou uitmaken van de Collectie Meddens. De eerdere herkomst uit India is onbekend. 


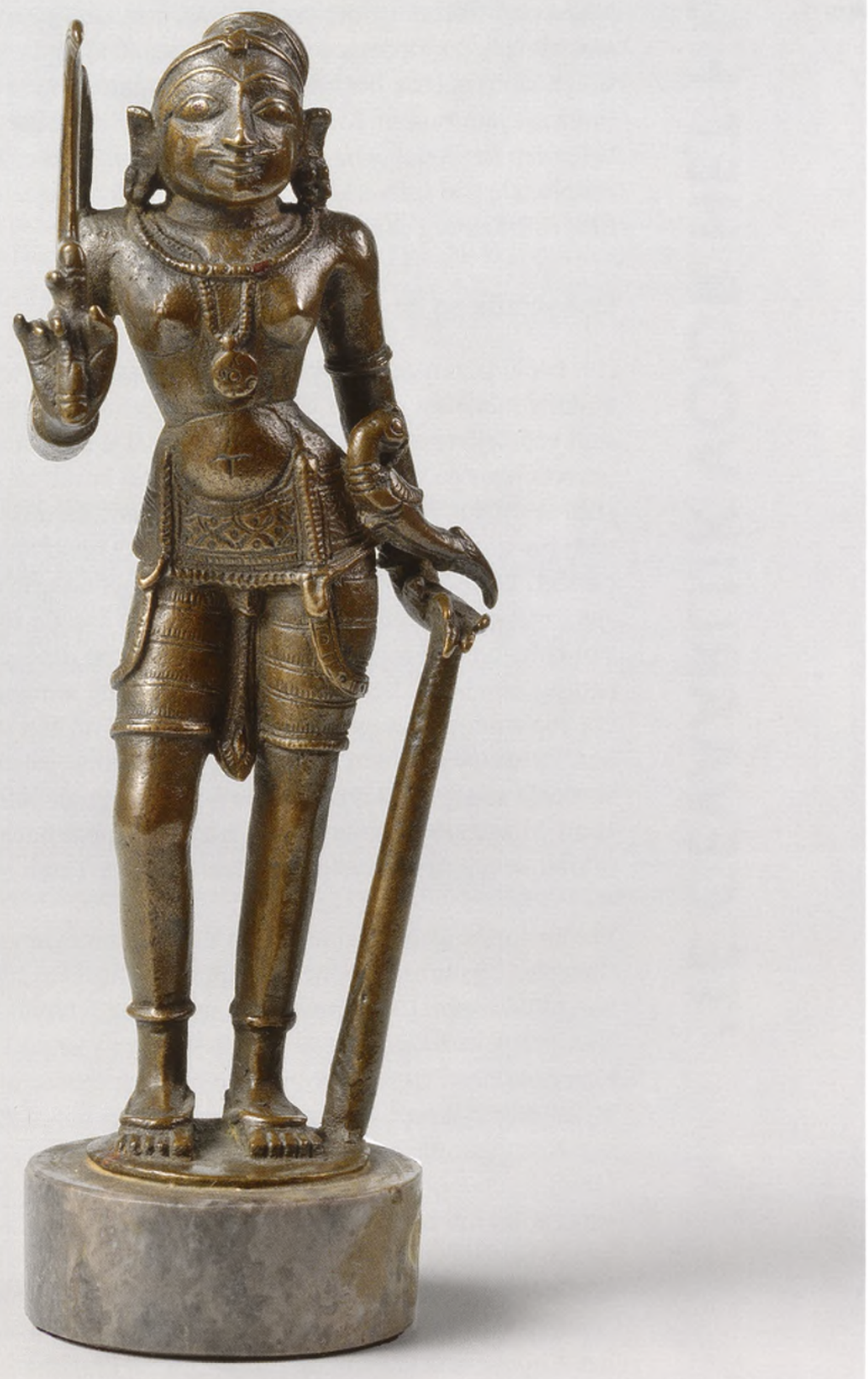


Afb. 1.

Karuppannasamy, gegoten brons, h. $14 \mathrm{~cm}$., India, Tamil Nadu, circa 1650-1700, AK-MAK-1736, bruikleen van de Vereniging van Vrienden der Aziatische Kunst.
Karuppannasamy wordt vereerd in het centrale gedeelte van Tamil Nadu, ongeveer in de streek tussen de steden Thanjavur en Tiruchirapalli (Trichy) in het noorden en Madurai en Sivaganga in het zuiden (deze laatste twee zijn de belangrijkste cultuscentra). ${ }^{5}$ Zijn schrijnen zijn vooral bekend bij de lokale bevolking en bij personen voor wie hij de familiegod is. Vele tempels staan in landelijk gebied tussen de akkers of helemaal in de wildernis, ver van de beschaving. De meeste schrijnen zijn oorspronkelijk vrij eenvoudig van vorm: een platform met daarop een godenbeeld, omringd door het groen. Er is vaak geen omheining en de gelovige moet zelf bepalen waar het tempelterrein begint om daar eerbiedig de schoenen uit te trekken. In de laatste jaren echter ondergaan veel lokale heiligdommen een facelift die ze langzaam in 'complete' tempels verandert: de ruimte rondom het godenbeeld krijgt echte wanden en een dak, het grasveld wordt cement, en het geheel wordt omringd door een hoge muur. Dit heeft te maken met de stijgende welvaart en, wellicht, de wens om de status van de cultus te verhogen. (Om dezelfde reden worden er soms beelden van de pan-Indiase goden geïnstalleerd.) ${ }^{6}$ Bovendien dijen veel steden aanhoudend uit en een tempel die jaren geleden nog tussen de rijstvelden stond, bevindt zich inmiddels in een drukke woonwijk. Hoewel klein en eenvoudig, blijken deze plattelandstempels voor de lokale bevolking vaak belangrijker dan de tempels van de 'grote goden'. De locatie van de schrijn wordt gewoonlijk niet door mensen bepaald, maar door de god zelf. Er bestaan verhalen over enorm grote rotsblokken die niet van het veld weggevoerd konden worden, over kleine objecten zoals een steentje of een stukje hout die plots zo zwaar worden dat men ze niet langer dragen kon, over koeien die spontaan op een bepaalde plek melk gaven, enzovoorts. Dit alles wordt als een goddelijk teken geïnterpreteerd: de god wil blijkbaar op die specifieke plek vereerd worden. Over Karuppannasamy wordt verteld dat zijn beeld in een houten doos aan de rivieroever aanspoelde. Waar dat precies plaatsvond, is onduidelijk maar de god zou in ieder geval uit Kerala komen. Er zijn talloze versies van het verhaal en elke tempel schijnt er eentje te hebben: Karuppannasamy zou in het water gegooid zijn door een boze priester wiens zoontje hij heeft gedood; of de priester in zijn tempel werd te oud om voor hem te zorgen; of hij ging naar Kerala om zwarte magie te leren. Vele overleveringen noemen een lokale vorst als een van de 'ontvangers' van de god en sommige verbinden Karuppannasamy met pan-Indische mythen. De op het gebouw toegesneden versies worden vooral aan buitenstaanders verteld (inclusief buitenlandse onderzoekers!), terwijl het 'echte' verhaal geheim blijft, om misbruik te voorkomen en uit angst de god te beledigen met alle consequenties van dien. Helaas zullen de oude, plaatsgebonden verhalen waarschijnlijk langzamerhand verdwijnen. In het digitale tijdperk worden lokale mythes gestandaardiseerd en aangepast tot een 'juiste', 'beschaafde' versie.

\section{De plaats in de tempel}

Antropologen hebben de 'dorpsgoden' (Sanskriet: gramadevata) grofweg verdeeld in 'hoofdgoden' en 'wachters', wat af te lezen valt aan hun positie binnen de tempel. ${ }^{7}$ De hoofdgod is te vinden in het centrum van het complex, zijn schrijn is geplaatst op de oost-west as. Hij wordt omringd door 'secundaire goden', die het complex bewaken. ${ }^{80}$ Karuppannasamy kan beide rollęn access 
vertolken. Als wachter is hij aanwezig in tempels van de Godin (Devi) en die van Aiyanar, een razend populaire god die vrijwel overal in Tamil Nadu vereerd wordt. ${ }^{9}$ Zeer karakteristiek voor Aiyanar-tempels zijn de meer dan levensgrote figuren van paarden ( $a f b .2$ ), voorheen veelal gemaakt van klei en rijk versierd, maar tegenwoordig meestal vervaardigd van beton (dat veel sneller droogt dan klei en daarom moeilijker te modelleren is). Volgens de lokale geloofsovertuiging gaan Aiyanar en Karuppannasamy's nachts te paard om het dorp en de velden te beschermen.

De schrijn van Karuppannasamy bevindt zich meestal vrij dichtbij die van Aiyanar, aan de linkerzijde. Daarnaast is er in de tempel nog een aantal andere afbeeldingen van de god te vinden, ${ }^{10}$ zoals het, meest spectaculaire, beeld van Karuppannasamy op een galopperend paard. Het feit dat hij, als enige naast Aiyanar zelf, op deze manier afgebeeld wordt, spreekt van zijn - letterlijk - hoge positie in Aiyanar-tempels (afb. 3).

Heel soms zijn Karuppannasamy-schrijnen in de tempels van de 'grote goden' te vinden. De bekendste is Alagar Koil, een belangrijke Vishnu-tempel in de buurt van Madurai, waar Karuppannasamy voorgesteld wordt in de abstracte vorm van achttien trappen.

\section{Te gevaarlijk voor het huisaltaar}

In tegenstelling tot de goden van het pan-Indiaas pantheon (met uitzondering van de Godin) zijn de meeste dorpsgoden geen vegetariërs (behalve de sterk 'gebrahmaniseerde' Aiyanar). Ook Karuppannasamy houdt van bloedoffers en er worden in zijn tempels regelmatig kippen en geiten geslacht. Er zijn slechts enkele tempels waarin vleesloos geofferd wordt aan Karuppannasamy, hetgeen misschien een latere ontwikkeling is, bedoeld om de cultus aantrekkelijker te maken voor een breder publiek. De niet-vegetariër-goden hebben de naam woest en onvoorspelbaar te zijn. Daarom wordt Karuppannasamy nooit thuis vereerd, behalve door zijn priesters en anderen die een bijzondere band met hem hebben. Zelfs dan wordt zijn icoon meestal op het erf geïnstalleerd en niet binnenshuis in de puja-kamer (de ruimte waarin kleine godenbeelden bewaard en dagelijks vereerd worden). De god zou, geërgerd door incorrecte verering of het overschrijden van zuiverheidsregels de huisbewoners ernstig kunnen straffen met ziekte en misschien zelfs met de dood. Door deze voorkeur voor dierenoffers worden de tempels van Karuppannasamy over het algemeen door de vegetarische kasten, met de Brahmanen voorop, strikt gemeden. Wie zijn dan wel de aanbidders van deze god? Karuppannasamy schijnt een bijzondere band te hebben met een aantal 'communities' (zoals men het tegenwoordig in India liever noemt), onder andere de Kallars (ook bekend als Thevars), wier traditionele bezigheid, volgens overlevering, bestond uit het stelen van vee en struikroverij. In de loop der eeuwen fungeerden zij meer en meer als dorpswachters (hetgeen hen verbindt met Karuppannasamy die ook de functie heeft van een wachter). Tegenwoordig zijn zij meestal grootgrondbezitters, vooral in de districten van Madurai, Sivaganga, Pudukkottai en Thanjavur. Een andere groep voor wie Karuppannasamy erg belangrijk is zijn de Velars, traditioneel de makers van de terracottafiguren van de god (en zijn paarden), en tevens de priesters van Karuppannasamy. Sommige tempels zijn eigendom van Dalit-gemeenschappen (voorheen: 'kastelozen'). Ik ken slechts één geval waarin de priester een Brahmaan is." 
Afb. 2

Aiyanar-tempel in de buurt van Pondicherry.

Afb. 3

Aiyanar-tempel met een belangrijke Karuppannasamyschrijn, Keelakuyilkudi, Madurai district.
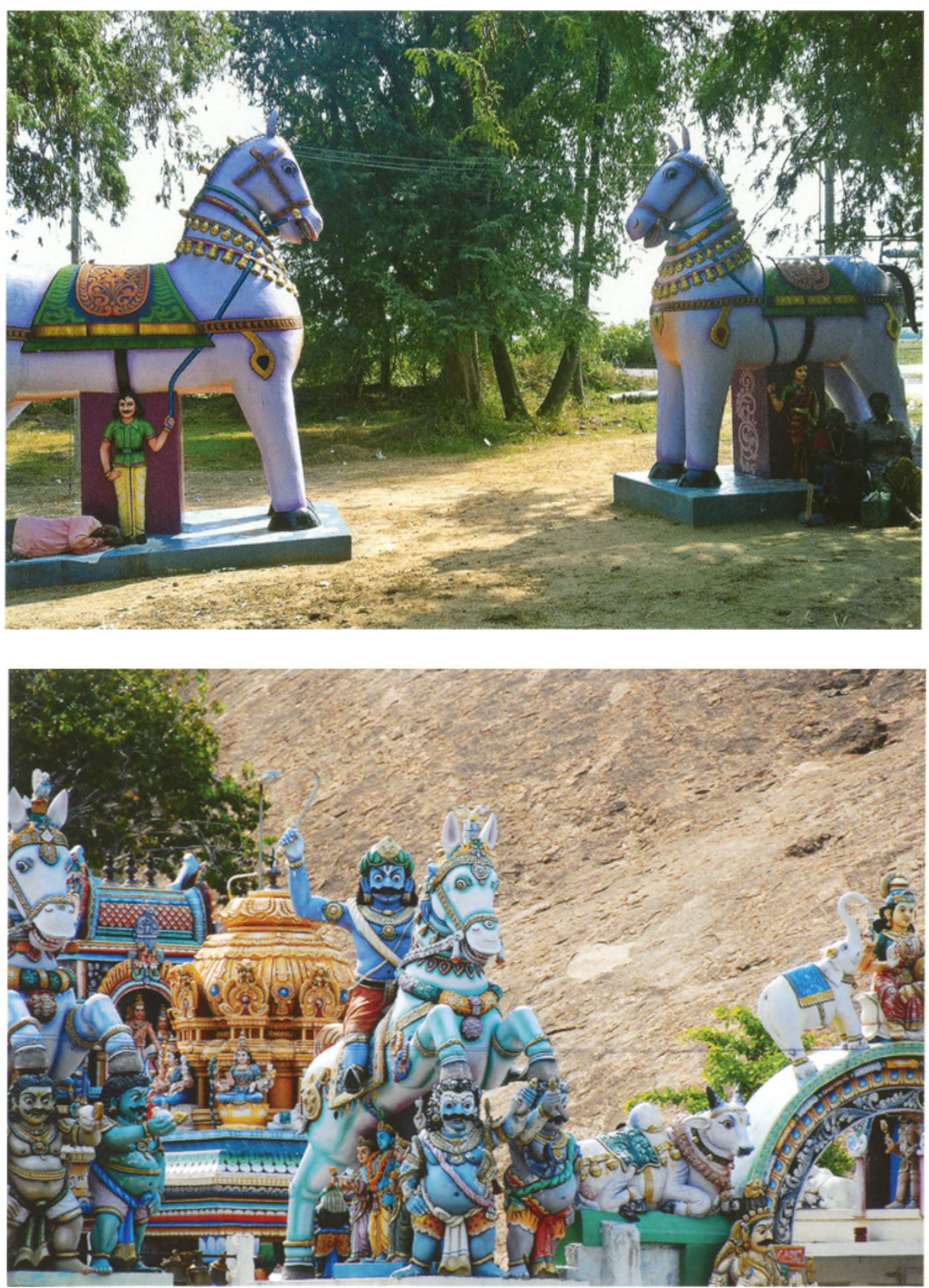

\section{Het mysterie van metalen beelden}

Metalen beelden van Karuppannasamy zijn schaars. Over het algemeen zijn beelden van gramadevata's (dorpsgoden) gemaakt van steen (afb. 4), klei (afb. 5) of - in een enkel geval - van hout. Brons en messing zijn duur en konden in het verleden waarschijnlijk niet worden bekostigd door de dorpsbewoners. ${ }^{12}$ Tegenwoordig worden bronzen beelden wel af en toe geproduceerd, op bestelling van de Karuppannasamy-priesters, ${ }^{13}$ maar hoe oud deze traditie is, is onbekend. Ik kon slechts vijf metalen exemplaren traceren die qua iconografie op 'onze' Karuppannasamy lijken en ook ouder zijn dan de $20^{e}$ eeuw: drie waren begin jaren 60 gefotografeerd door het French Institute of Pondicherry (IFP), ${ }^{14}$ één staat in het depot van het Chennai Government Museum (circa 1800) en één behoort tot een privécollectie. ${ }^{15}$ In tempels van pan-Indiase goden worden bronzen beelden tijdens festivals rondgedragen access 


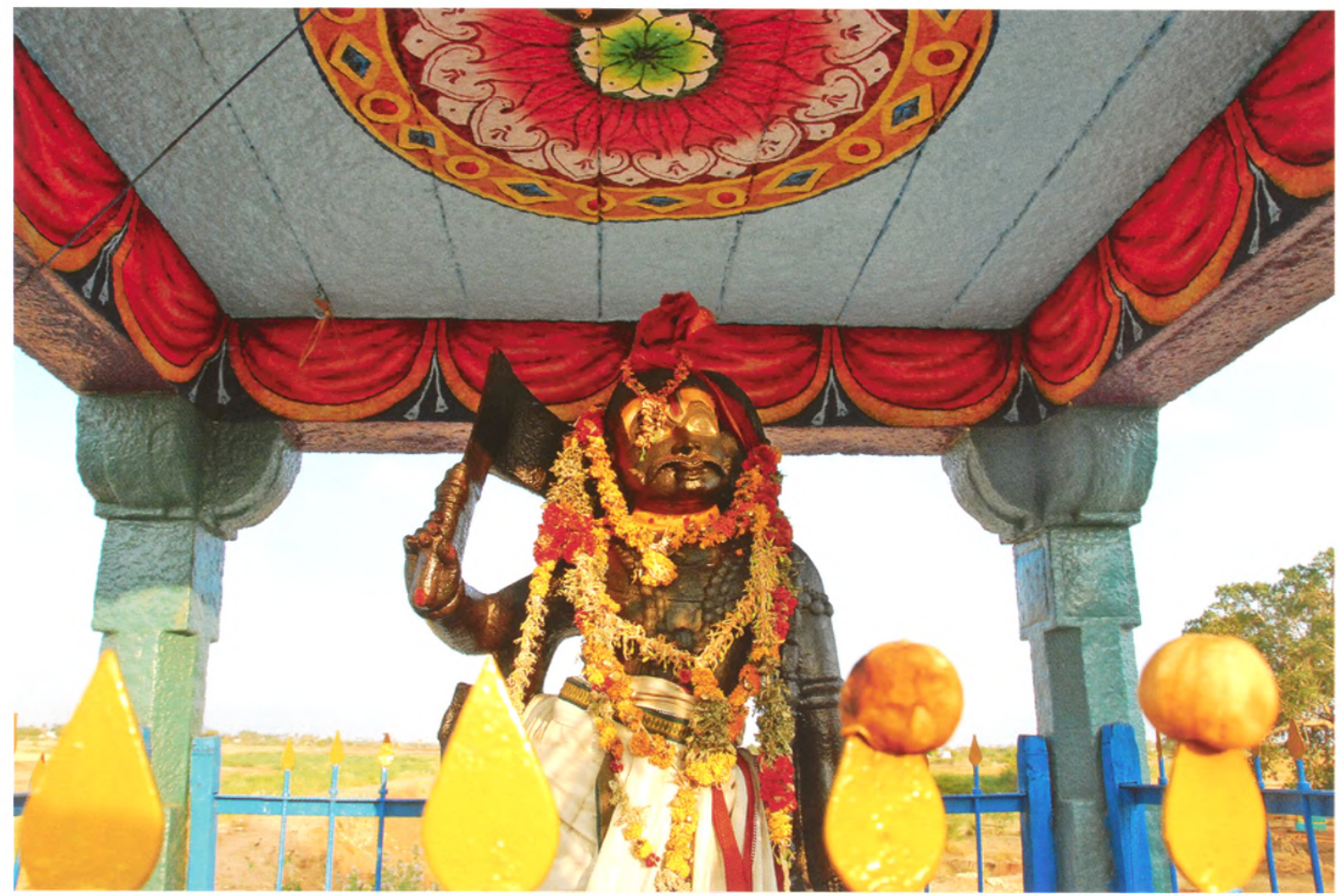

Afb. 4 Een openlucht-schrijn van Karuppannasamy in een Aiyanar-tempel, Keela Urappanur, Madurai district. in processie. Aangezien de bovengenoemde beeldjes allemaal erg klein zijn $(10-20 \mathrm{~cm}$.) om als een processiebeeld te dienen, blijft hun functie nogal mysterieus.

\section{Datering Karuppannasamy in het Rijksmuseum}

Stilistisch lijkt het beeld het meest op (kunst)voorwerpen uit het einde van de Nayaka-periode (midden-16 - vroeg-18 eeuw). Op de tempels van de Nayaka's zijn vaak 'gewone mensen' afgebeeld, meestal geïnterpreteerd als begunstiger. Hun gelaatstrekken, de haardracht en sieraden, in het bijzonder de oorbellen en de diadeem, vertonen sterke overeenkomsten met 'onze' Karuppannasamy. Twee personen dragen zelfs een kort mes met het handvat in de vorm van een parkiet (afb. 6). ${ }^{16} \mathrm{Wij}$ zouden dus voorzichtig kunnen stellen dat het beeld uit circa 1650-1700 dateert, maar verder onderzoek is zeker gewenst. Het is theoretisch mogelijk dat de Karuppannasamy later 'in de Nayaka-stijl' gemaakt werd, hoewel de hoge esthetische kwaliteit van het beeld een veel latere datering tegenspreekt.

\section{Twijfels en toekomstig onderzoek}

In februari 2014 vertrok ik naar India om onderzoek te doen naar Karuppannasamy. Mijn contactpersoon en gids zou de heer Saravanan zijn, een traditioneel kunstenaar en priester, voor wie Karuppannasamy de familiegod was. Daarnaast was hij een van de weinigen die in zijn pujakamerbeelden van Karuppannasamy had die hij dagelijks vereerde. Een perfecte begeleider dus. Helaas heeft de heer Saravanan twee dagen na majo $11: 30: 41 \mathrm{Am}$ 
aankomst in India een ernstig ongeluk gehad en is hij vier dagen later overleden. Na deze tragische gebeurtenis bleek het onmogelijk om op korte termijn een andere gids te vinden. Vele vragen blijven voorlopig onbeantwoord, door het noodlottig overlijden van mijn contactpersoon en gids, maar ook omdat het onderwerp uiterst exclusief is (de god wordt alleen in een bepaalde streek vereerd, door bepaalde gemeenschappen), en omdat de tempels moeilijk toegankelijk zijn, de lokale bevolking geen Engels of Hindi spreekt, en schriftelijke bronnen ontbreken terwijl de orale traditie vaak hermetisch gesloten blijft voor buitenstaanders. Een vraagstuk bijvoorbeeld dat voorlopig onbeantwoord blijft, betreft de schaarste en de oorspronkelijke functie van metalen beelden. In geen van de door mij bezochte tempels (vooral in de omgeving van Madurai) ben ik dergelijke beelden tegengekomen, ook de betrokken priesters konden hierover geen informatie verschaffen. Helaas is het mij niet gelukt om naar de drie tempels te gaan die begin jaren 60 metalen beelden van Karuppannasamy huisvestten (zie noot 14). Het is onbekend hoe en wanneer die beelden daar terecht zijn gekomen. Verder, hoewel de context voor het VVAK-beeld ontbreekt, is het misschien enigszins te achterhalen door de studie van iconografische kenmerken. Het is op dit moment onbekend wat de belangrijkste determinanten zijn van de (variërende) iconografie van de god: is het de streek waar het beeld vandaan

Afb. 5

Een stenen Karuppannasamy (binnen de schrijn) en een terracotta Karuppannasamy (erbuiten). Aiyanartempel, Ponmeni, Madurai.

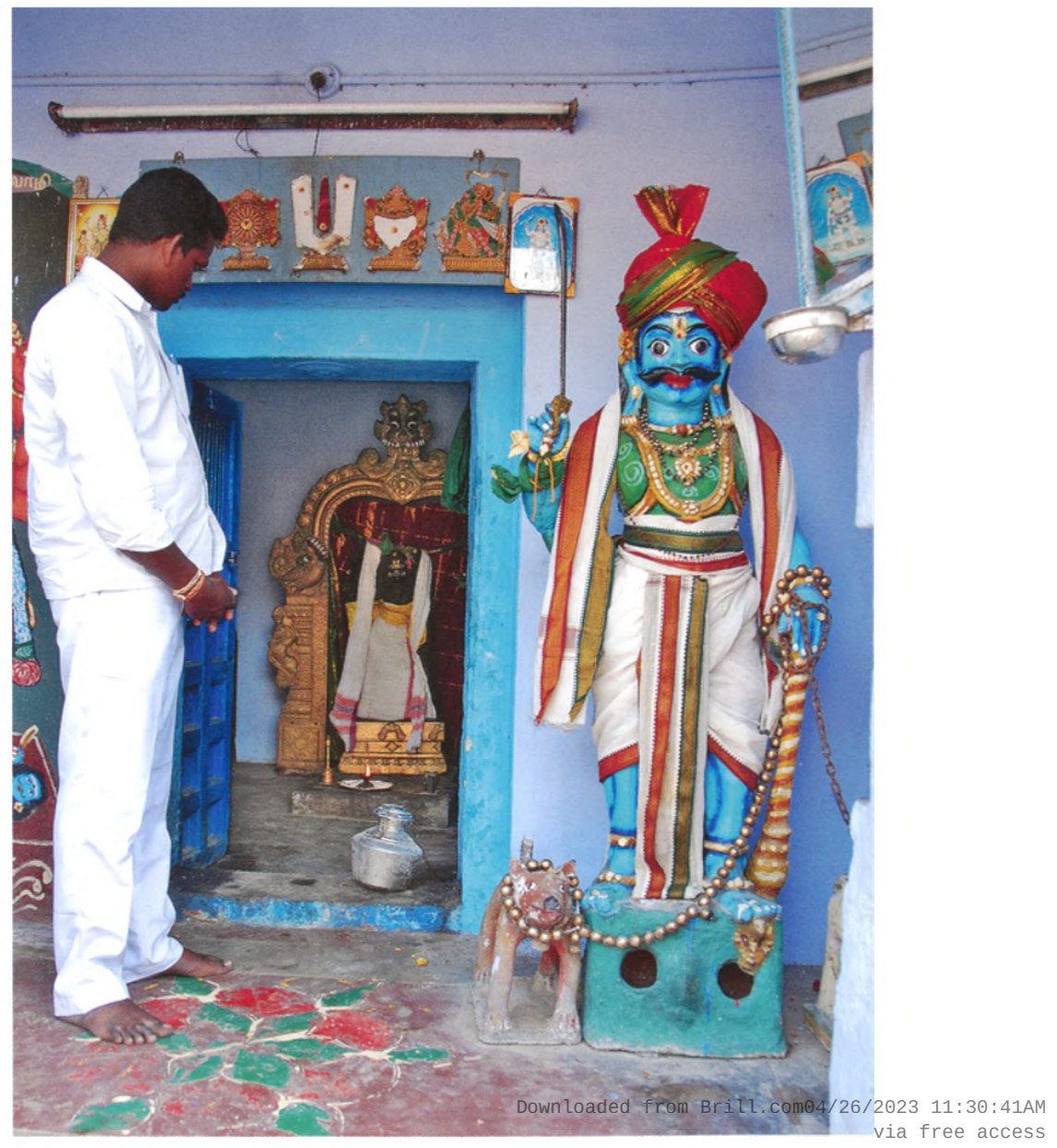


komt, of misschien toch vooral de gemeenschap? Tot nu toe zijn er vooral cultureel-antropologische studies naar de Tamil plattelandsgoden gepubliceerd, maar die concentreren zich op andere kwesties dan gebruik van materialen en iconografie. Het gebrek aan basiskennis is onder andere te merken aan de incorrecte identificatie van de beelden, gefotografeerd door het IFP (zie noot 14). Een brede, vergelijkende iconografische studie zou wellicht het antwoord kunnen bieden.

Het parkiet-mes van onze Karuppannasamy is iconografisch uiterst bijzonder. Tot nu toe heb ik dit op geen enkel ander beeld van de god gezien. ${ }^{17}$ Het zou interessant zijn om te weten of het, behalve op de twee bovengenoemde figuren in Nayaka-tempels, ook elders, bijvoorbeeld in wapencollecties, voorkomt. Dit zou misschien een preciezere datering kunnen opleveren. Volgens sommigen verwijst de parkiet op de schouder van Karuppannasamy naar zijn mildere karakter, behorend bij de 'Cinna' (de 'kleine' Karuppu). Verder is de parkiet ook het symbool van Meenakshi, de godin van Madurai. Heeft de vogel hier een symbolische betekenis of is het puur en alleen te danken aan de fantasie van de kunstenaar? Tot slot zou het interessant zijn om te onderzoeken hoe oud de Karuppannasamy-cultus is. Het is bekend dat beelden van Aiyanar al in de Pallava-periode (laat $8^{\text {e }}$ eeuw) bestonden, maar over Karuppannasamy ontbreekt alle informatie. Inscripties en oude Tamil-verhalen zouden hier misschien uitkomst kunnen bieden. Ik hoop in de toekomst op z'n minst enkele van deze vragen te kunnen beantwoorden.

Het geschenk van de heer Polak is dus een bijzonder object dat aanleiding kan zijn tot een nieuw, internationaal belangrijk onderzoek.

- Dr. Anna Slaczka is conservator Indiase kunst bij het Rijksmuseum. Zij promoveerde (2006) in Leiden op het gebied van Sanskriet en Indiase kunst. Ze richt zich momenteel op contacten tussen Zuid- en Zuidoost-Azië, iconografische Sanskrietteksten, kunst en architectuur van India en hindoetempelrituelen.

\section{Noten}

1. Fotografie: Anna Slaczka (m.u.v. afb. 1).

2. Wel soms in etnografische musea. Het Tropenmuseum, Amsterdam, heeft een vaste tentoonstelling Het paard van Aiyanar dat gaat over de 'dorpsgoden' uit Tamil Nadu, met daarin een terracotta-afbeelding van Karuppannasamy (R-540).

3. Karuppannasamy is volgens sommige overleveringen verbonden met Vishnu. Zijn connectie met Krishna, de bekendste Vishnu-avatar, is te zien in zijn naam: 'karuppu' is het Tamil equivalent van het Sanskriet 'krishna' (zwart). Zoals Krishna en Vishnu, wordt Karuppannasamy vaak blauw voorgesteld, de kleur die in de Indiase kunst een wat donkere huid aanduidt.

4. Letterlijk: 'black elder brother god'. Er bestaan allerlei varianten van deze naam: Karuppannaswamy, Karuppu, Karuppan en nog veel meer.

5. Zoals aangegeven door E. Masilamani-Meyer, Guardians of Tamilnadu, Halle, 2004, p. 254 (Table I), maar er zijn ook enkele Karuppannasamy-schrijnen in de omgeving van Salem en zelfs Coimbatore (Masilamani-Meyer 2004: 232-7).

6. Zoals in de Aiyanar-tempel in Ponmeni, Madurai.

7. Masilamani-Meyer 2004: 89-113.

8. Tegenwoordig zijn 'secondary deities' vaak belangrijker dan de 'main deities'. Het heeft te maken met het geleidelijk 'brahmaniseren' en 'milder worden' van de 



Afb. 6

Een mes met het handvat in de vorm van een parkiet. Pilaar-reliëf, Jambukesvara-tempel, Tiruchirapalli. hoofdgoden, onder andere Aiyanar. De 'secondary deities' worden beschouwd als 'staande dichter bij het volk' en bovendien woester en daardoor krachtiger.

9. Het Tropenmuseum heeft vorig jaar een bronzen beeld van Aiyanar gekocht $\left(15^{\mathrm{c}}\right.$ eeuw; 6473-1). Helaas staat het beeld nu in het depot.

10. In tegenstelling tot Aiyanar en de pan-Indiase goden, maar wel zoals de meeste 'woeste goden', is Karuppannasamy vrijgezel. De vrouwelijke figuren die (heel) soms naast hem te vinden zijn, zouden zijn 'zuster' voorstellen.

11. Masilamani-Meyer 2004: 25.

12. Uitzonderingen zijn Aiyanar en sommige godinnen. Zie noot 8 .

13. Zoals mij verteld werd door de maker ervan, de traditionele bronsgieter en eigenaar van Eeswari Sculptures, Tiruvalanjuli (Thanjavur district).

14. De beelden stonden in een Aiyanar-tempel in Kovil Esanai, een Shiva-tempel, Melappanaiyur, en een Aiyanar-tempel, Perungalur (allemaal in Tiruchirapalli district). Het IFP-archief heeft meerdere foto's gearchiveerd als 'Karuppannasamy', die metalen beelden van een 'volksgod' laten zien, maar in alle andere gevallen is de identificatie incorrect.

15. Plus nog één twijfelachtig geval in het Salar Jung Museum in Hyderabad, gelabeld als een $17^{\mathrm{e}}$-eeuwse Balarama (M.S-3295). In Zuid-India ligt de iconografie van Balarama dicht bij die van Karuppannasamy.

16. Respectievelijk in de Ranganathaswamy- en de Jambukesvara-tempels in Tiruchirapalli. Aangezien er ook andere overeenkomsten zijn, zou dit mogelijk de periode kunnen zijn waarin de iconografie van de god zich ontwikkelde.

17. Hierbij moet gezegd worden dat afbeeldingen 'under worship' vrijwel altijd gewikkeld zijn in een stof die de heupen en bovenbenen bedekt. 